\title{
An Asymptomatic Small-Cell Bladder Cancer Until Bilateral Ureteral Obstruction Happened
}

\author{
Aslan Demir ${ }^{\mathrm{a}, \mathrm{c}}$, Yasemen Adali ${ }^{\mathrm{b}}$, Kursat Cecen ${ }^{\mathrm{a}}$, Mert Ali Karadag ${ }^{\mathrm{a}}$, Mehmet Uslu ${ }^{\mathrm{a}}$, \\ Omer Erkam Arslan ${ }^{\mathrm{a}}$, Nilhan Eryegen Uzlu ${ }^{\mathrm{b}}$
}

\begin{abstract}
Small-cell bladder cancer is a rare form and composes less than $1 \%$ of primary bladder malignancies. We present a case with a large small-cell bladder cancer leading to acute kidney failure clinic without gross hematuria. Computed tomography revealed that all the bladder walls were invaded by the extensive tumor and bilateral hydronephrosis. Double J stent for left side and nephrostomy tube for the right side were inserted, and bladder biopsy was taken by transurethral resection. Pathologic examination revealed small-cell bladder cancer. The patient did not accept chemotherapy. He died because of the acute renal failure 4 months later since the beginning.
\end{abstract}

Keywords: Small-cell bladder cancer; Renal failure; Ureteral obstruction

\section{Introduction}

Small-cell cancer (SCC) primarily originates from the lung [1]. Bladder cancer (BC) is the fourth most common cancer in men but small-cell bladder cancer (SCBC) is a rare form and composes less than $1 \%$ of primary bladder malignancies [2].

Available knowledge in the literature is based mainly on some retrospective series and case reports [3]. Although older age and smoking are putative risk factors for this type

\footnotetext{
Manuscript accepted for publication July 7, 2014

${ }^{a}$ Department of Urology, Kafkas University Faculty of Medicine, Kars, Turkey

${ }^{\mathrm{b}}$ Department of Pathology, Kafkas University Faculty of Medicine, Kars, Turkey

${ }^{\mathrm{c}}$ Corresponding Author: Aslan Demir, Kafkas Universitesi Tip

Fakultesi, Uroloji A.B.D, Kars, Turkey.

Email: draslandemir@yahoo.com
}

doi: http://dx.doi.org/10.14740/jmc1865w of carcinoma, the role of familial or genetic predisposition is uncertain [4]. The age, gender predilection and symptoms at presentation of SCBC are similar to those of bladder urothelial carcinoma [5]. The most common presenting symptoms such as painless hematuria, dysuria, obstructive voiding symptoms, weight loss, abdominal pain and/or recurrent urinary tract infections as seen in $\mathrm{BC}$, can occur in the patients with SCBC $[1,5]$.

In this case report, we present a case with a large SCBC leading to acute kidney failure.

\section{Case Report}

A 58-year-old male patient was admitted to our clinic with dysuria, nocturia and pollacuria happening for 1 month. He had no smoking and gross hematuria history in his health past. He was a farmer. His PSA level (2.1 ng/dL), urine analysis test results were at normal level and no bacteria were cultured in his urine culture. Although an antibiotic regimen including ciprofloxacin group was given for 7 days, his complaints increased and nausea and anorexia occurred. His creatinine level was 2.1 and urea was 65 at that time, and urinary system ultrasonography revealed that a bilateral grade 2 hydronephrosis in his kidneys and thickness of his bladder wall was measured as $24 \mathrm{~mm}$. It was not established residual urine was in his bladder but the patients was catheterized for urine output follow-up. Two days later, his urine output stopped and creatine level increased up to 5.3. Non-contrast abdomen computed tomography (NCCT) was performed and an increased bilateral hdyronephrosis was established on NCCT sections (Fig. 1). NCCT also revealed that all the bladder wall thickness increased. Bilaterally double $\mathrm{J}$ ureteral stent insertion was planned to deal with hydronephrosis and bladder biopsy for pathological diagnosis. Cystoscopy revealed that tumor had been already extended to nearly all bladder walls. Right ureteral orifice was not seen, but the left one was hardly seen and a double J ureteral stent was inserted. Afterwards, transurethral resection (TUR) was performed. His creatine level increased after for a while progressively while not establishing prerenal or renal insufficiency by the internist. But the patient's general health 

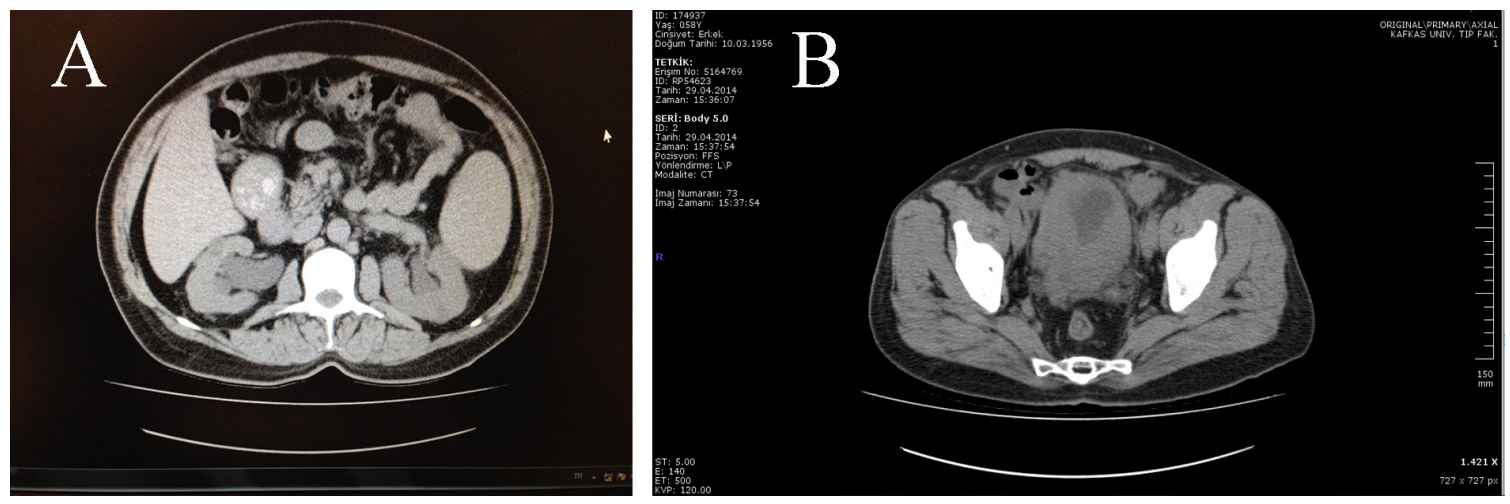

Figure 1. (A) Prominent at the right side bilateral hydronephrosis depending on obstruction of the bilateral ureteral orifices by the extensive bladder tumors. (B) Extensive bladder tumor image on CT transverse section.

status went bad progressively. His creatine level increased up to 8.5 and $\mathrm{NaHCO}_{3}$ was given in order to prevent metabolic acidosis. His creatine level started to decrease after a nephrostomy tube was inserted for the right side. After these managements, the patient's general health status went well. Pathological examination revealed a small-cell carcinom of the bladder (Fig. 2). NCCT did not reveal any metastatic signs. A chemotherapy regimen was planned, but the patient did not accept it and died 4 months after the first diagnosis.

\section{Pathological examination}

Macroscopic examination revealed $0.3 \mathrm{cc}$ volume, ragged, irregularly shaped and gray white tissue. Microscopy showed a diffuse patternless type growth of loosely cohesive, relatively uniform and small round to oval cells with powdery (salt-and-pepper) nuclear chromatin and scant cytoplasm. Mitotic figures and apoptotic bodies are commonly observed. The neoplastic cells on immunohistochemistry ex-

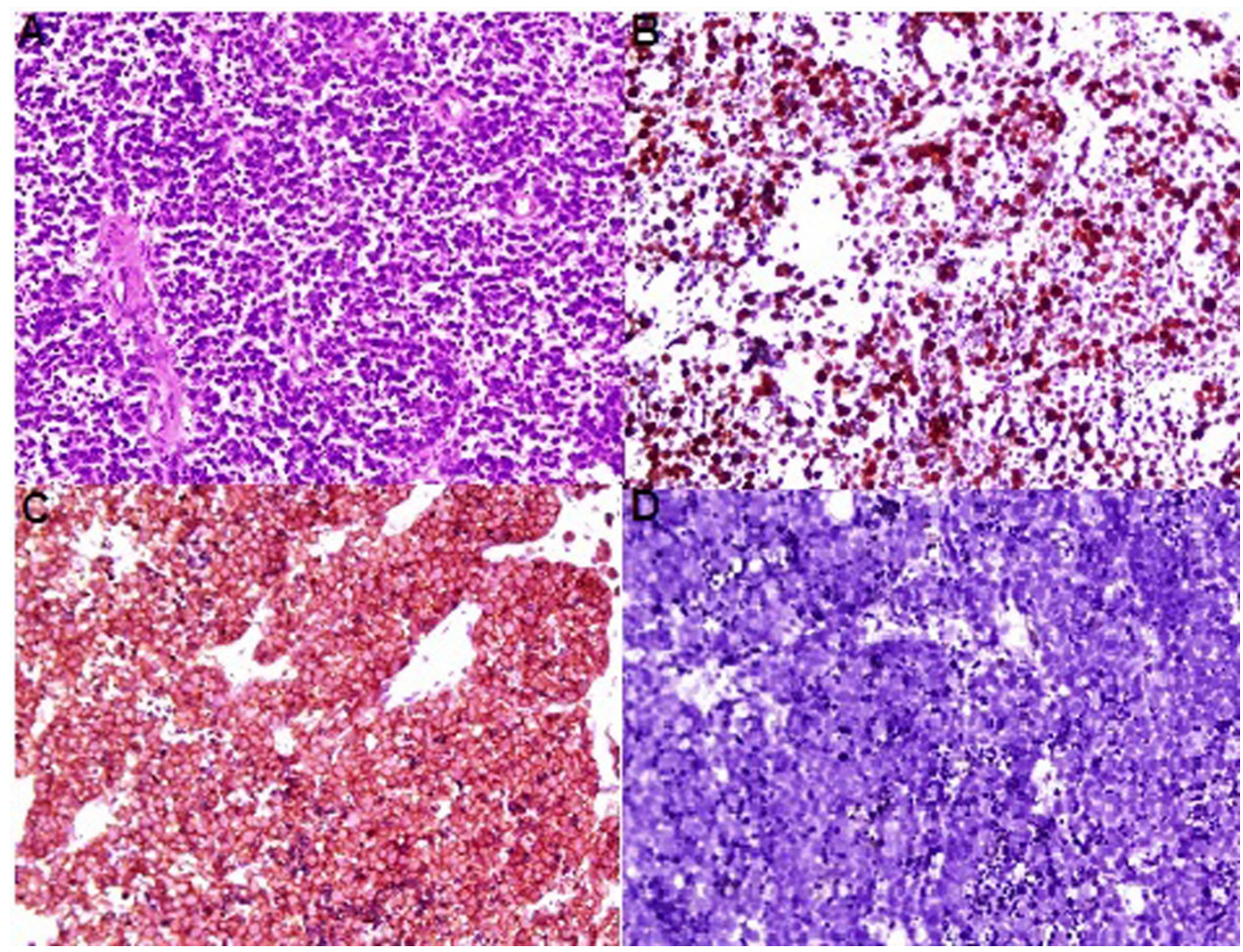

Figure 2. (A) Diffuse infiltrative tumor cells, small round to oval cells with powdery (salt \& pepper) nuclear chromatin and scant cytoplasm. (B) The tumor cells are forcytokeratin-positive. (C) The tumor cells are synaptophysin-positive. (D) The tumor cells are negative for LCA. 
hibited cytokeratin and diffuse synaptophysin positivity, and were negative for chromogranin A and leucocyte common antigen (LCA) (Fig. 2).

\section{Discussion}

SCBC commonly affects men (men/women ratio is 3.8:1 [3, $6,7]$ ) in their seventh or eighth decade of life [2], and the patient in our case was 58 years old.

Numerous hypotheses have been proposed for the origin of SCBC, three of which have gained prominence. The first so-called stem cell theory, postulates a cancer stem cell, which then differentiates into diverse cell types. This is suggested by the occurrence of SCBC together with other types of bladder tumors [6]. A second view suggests the origin of SCBC from malignant transformation of neuroendocrine stem cells that are found within the urothelium and bladder [8]. The third hypothesis is that SCBC originates from extreme metaplasia of urothelial cells [2].

Smoking is the strongest risk factor in the $50-70 \%$ of patients with SCBC [5], but the patient in our case had no smoking history.

Painless gross hematuria and local irritative symptoms such as dysuria, pelvic pain, urinary obstruction, urinary infections, sometimes anorexia, and fatigue and weight loss are some of the symptoms $[1,2,9]$ as they existed in our case. The clinical features in our case mostly depend on the acute renal failure.

Ultrasonography in our case revealed an increase in bladder wall up to $24 \mathrm{~mm}$. NCCT revealed that all bladder walls increased as it looks like in carcinoma in situ (Fig. 1) as well as bilateral grade 2 hydronephrosis. However, the final diagnosis of SCBC is based on pathological examination of the tumor tissue obtained by TUR. Also, the common cellular pattern is diffuse sheets of dark blue cells with necrosis and mitosis [1]. Neuroendocrine markers, such as chromogranin A, synaptophysin, CD56 and neuron specific enolase (NSE) are often focally or diffusely positive for these cancers by immunohistochemical methods [10]. However, the absence of staining for these markers does not rule out the diagnosis of SCBC, and diagnosis relies on microscopic findings [2]. The microscopic examination of our case showed a diffuse patternless type growth of loosely cohesive, relatively uniform, small round to oval cells with powdery (salt-and-pepper) nuclear chromatin and scant cytoplasm (Fig. 2).

There are no standard guidelines for SCBC treatment due to its rarity. Treatment decisions are usually based on retrospective studies and case reports [2]. Because SCBC is more aggressive than the conventional ones, it should be treated as metastatic disease, even there is no radiologic evidence [1, 3]. We also could not establish any metastases. SCBC management is not well-known and it is usually treated as smallcell lung cancer with the exception that surgical therapies are often an important part of management in SCBC [4]. A study did not reveal any difference in patients treated with or without cystectomy; however, the 5-year cancer-specific survival rate was only $16 \%$ [7]. But neoadjuvant chemotherapy followed by surgery (in case of a surgically resectable tumor is existing) can result in a 5-year survival of $80 \%$ [4]. Chemotherapy can be useful for all stages of SCBC among patients who were treated with TUR, but it is not effective in addition to cystectomy [1]. A variety of chemotherapeutic regimens have been used, but carboplatin or cisplatin and etaposide is the current treatment of choice [1]. Although chemoradiation therapy is the primary management for the SCBC, the experience combining chemotherapy with radical cystectomy for primary SCBC has shown equal, or better, local control and cancer-free survival than that was found with chemoradiation [1]. However, with 5-year disease-specific survival rates of $16 \%$ to $18 \%$ with chemoradiation or chemotherapy and radical cystectomy, respectively, the primary method to improve survival will be more effective treatment [1].

\section{Acknowledgement}

None.

\section{Conflict of Interest}

None.

\section{References}

1. Wood DP. Urothelial Tumors of The Bladder. In: Kavoussi LR, Novick AC, Partin AW, Peters CA, eds. Campbell-Walsh Urology, 10th edition, Vol. 4, Chapter 80. Elsevier, Saunders; 2012:2332.

2. Thota S, Kistangari G, Daw H, Spiro T. A clinical review of small-cell carcinoma of the urinary bladder. Clin Genitourin Cancer. 2013;11(2):73-77.

3. Pervez N, El-Gehani F, Joseph K, Dechaphunkul A, Kamal M, Pertschy D, Venner P, et al. Genitourinary smallcell carcinoma: a single-institution experience. Curr Oncol. 2013;20(5):258-264.

4. Bhatt VR, Loberiza FR, Jr., Tandra P, Krishnamurthy J, Shrestha R, Wang J. Risk factors, therapy and survival outcomes of small cell and large cell neuroendocrine carcinoma of urinary bladder. Rare Tumors. 2014;6(1):5043.

5. Zhao X, Flynn EA. Small cell carcinoma of the urinary bladder: a rare, aggressive neuroendocrine malignancy. Arch Pathol Lab Med. 2012;136(11):1451-1459.

6. Blomjous CE, Vos W, De Voogt HJ, Van der Valk P, Meijer CJ. Small cell carcinoma of the urinary blad- 
der. A clinicopathologic, morphometric, immunohistochemical, and ultrastructural study of 18 cases. Cancer. 1989;64(6):1347-1357.

7. Cheng L, Pan CX, Yang XJ, Lopez-Beltran A, MacLennan GT, Lin H, Kuzel TM, et al. Small cell carcinoma of the urinary bladder: a clinicopathologic analysis of 64 patients. Cancer. 2004;101(5):957-962.

8. Oesterling JE, Brendler CB, Burgers JK, Marshall FF, Epstein JI. Advanced small cell carcinoma of the bladder. Successful treatment with combined radical cys- toprostatectomy and adjuvant methotrexate, vinblastine, doxorubicin, and cisplatin chemotherapy. Cancer. 1990;65(9):1928-1936.

9. Starownik R, Korolczuk A, Bar K, Plaza P, Kis J, Muc K, Bar M. Partial cystectomy in a 76 year old patient suffering from small cell carcinoma of the urinary bladder. Cent European J Urol. 2013;66(2):159-162.

10. Ahmad O, Williams N, Chisholm N, Diab M, Khattak A, Forsyth L. Primary small cellcarcinoma of the bladder. Cent Eur J Urol. 2010;63:198-199. 